\title{
EDMUND HUSSERL
}

\section{Formale und transzendentale \\ Logik}

Versuch einer Kritik

der logischen Vernunft

2. Auflage

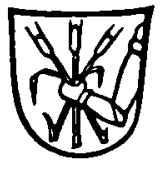

Max Niemeyer Verlag Tübingen 1981 
In: Jahrbuch für Philosophie und phänomenologische Forschung. Bd. X

Die vorliegende Ausgabe ist ein unveränderter Nachdruck. Die im „Erratum“ verzeichnete Änderung wurde, obwohl die gleiche Schrift nicht zur Verfügung stand, in den Text eingearbeitet. Die vorliegende Paginierung stimmt mit der in der 1. Auflage überein.

CIP-Kurztitelaufnahme der Deutschen Bibliothek

Husserl, Edmund:

Formale und transzendentale Logik : Versuch e. Kritik d. log. Vernunft / Edmund Husserl. 2. Aufl., unveränd. Nachdr. [d.] 1. Aufl. 1929. - Tübingen : Niemeyer, 1981.

ISBN 3-484-70129-3 kart.

ISBN 3-484-70128-5 Gewebe

ISBN 3-484-70128-5 Ln.

ISBN 3-484-70129-3 kart.

(C) Max Niemeyer Verlag Tübingen 1981

Alle Rechte vorbehalten.

Ohne ausdrückliche Genehmigung des Verlages ist es auch nicht gestattet, dieses Buch oder Teile daraus auf photomechanischem Wege zu vervielfältigen.

Printed in Germany.

Druck: Sulzberg-Druck GmbH, Sulzberg im Allgäu

Einband: Heinr. Koch, Tübingen 